\title{
Evaluation of Prognosis of Aortic Valve Stenosis: A New Approach Based on Transvalvular Energy Loss Index
}

\author{
Tanja Anguseva $^{1 *}$, Zan Mitrev $^{1}$, Predrag Milojevic ${ }^{1,2}$, Milka Zdravkovska $^{3}$ \\ ${ }^{1}$ Zan Mitrev Clinic, Skopje, Republic of Macedonia; ${ }^{2}$ University Clinic for Cardiovascular Surgery, University of Medicine, \\ Belgrade, Serbia; ${ }^{3}$ University of Medical Science, University Goce Delchev, Shtip, Republic of Macedonia
}

Edited by: Igor Spirosk Citation: Anguseva T, Mitrev Z, Milojevic P, Zdravkovska M. Evaluation of Prognosis of Aortic Valve Stenosis: A New Approach Based on Transvalvular Energy Loss Index OpenAccess Maced JMedSci. 2020 Nov30;8(B):1136-1143.
https://doi.org/10.3889/oamjms.2020.5498 https://doi.org/10.3889/oamjms.2020.5498 Keywords: Aortic stenosis; Transvalvular energy loss index; Clinical outcome *Correspondence: Tanja Anguseva, Zan Mitrev Clinic, Bledski Dogovor 8, Skopje 1000, Republic of Macedonia. E-mail: tanja.anguseva@zmc.mk Revised: $19-$ Nov-2020 Accepted: 24-Nov-2020
Copyright: $\odot 2020$ Tanja Anguseva, Zan Mitrev, Predrag
Milojevic, Milka Zdravkovska Milojevic, Milka Zdravkovska

Funding: This research did not receive any financial Competing Interests: The authors have declared that no competing interests exis Open Access: This is an open-access article distributed under the terns of the

\begin{abstract}
BACKGROUND: Estimation of aortic valve stenosis is not always sufficient based on standard parameters such as transvalvular pressure gradient (PG) or effective orifice area (EOA). We used transvalvular energy loss index (ELI) to provide more accurate information about myocardial reserve and patient's prognosis.

AIM: The aim of the study was to present the benefit of using ELI as a parameter that provides a more accurate estimation of aortic stenosis (AS) severity and influence on ventricular function. Second objective was to evaluate the performance of this index when predicting the mortality rate of patients

METHODS: In this follow-up trial from 2002 up 2020, we included 377 patients with reconstructive surgery of AS using bovine/equine pericardium, replacing valve cusps on patient's aortic fibrous ring. Leaflets were implanted separately, using continuous sutures with 2 supported stitches at newly created commissure, without stent or sowing ring. Using transesophageal ultrasound, intraoperatively and postoperatively, we measured EOA, PG, dimensions of aortic annulus, and sinotubular junction of ascending aorta. Applying Bernoulli equation $E L I=(E O A \times A A) /(A A-E O A)$ we calculated the values of ELI.

RESULTS: The results showed that ELI is influenced by both flow rate and aortic cross-sectional area (AA). Energy loss is systematically higher $(15 \pm 2 \%)$ in large aorta. ELI coefficient accurately predicted energy loss in all situations $\left(r^{2}=0.98\right)$. ELI was superior to EOA in predicting endpoints, such as early death after surgery. ELI $\leq 0.42 \mathrm{~cm}^{2} / \mathrm{m}^{2}$ strongly correlates with a higher mortality rate.

CONCLUSION: ELI has potential to reflect severity of AS better than EOA. It correlates with preserved myocardia reserve. ELI can be used like a parameter for estimating the pre-operative risk of death in patients with moderate/ severe AS.
\end{abstract}

\section{Introduction}

The assessment of the hemodynamic severity of the valvular stenosis is crucial when making a clinical decision. The American Heart AssociationAmerican College of Cardiology and the European Society of Cardiology-European Association for Cardio-Thoracic Surgery guidelines [1], [2], determine the stenosis severity generally by measuring the transvalvular pressure gradient (PG) of the aortic valve, the effective orifice area (EOA) (AVA); and the aortic valve replacement (AVR) which is considered a class I indication in patients with aortic stenosis (AS). If the stenosis is severe, the patient has symptoms or left ventricular ejection fraction (EF) $<50 \%$.

However, these conventional parameters are not sufficient to account for the extent of pressure recovery that may occur downstream of the stenosis or predict the clinical outcome after the surgical treatment. Transvalvular energy loss index (ELI) is a potential tool for providing valuable information which can improve the assessment of stenosis severity and risk stratification in aortic valve stenosis (AS). This index was mentioned for the first time in 2000, in an article published in Circulation by Hence [3]. Furthermore, in 2013, in a prospective study conducted by Bahlmann et al. [4], it was published that ELI provides independent and incremental prognostic information derived from conventional measures of AS severity. Authors of the sub-study of the Simvastatin Ezetimibe in AS (SEAS) trial reported that a $1 \mathrm{~cm}^{2} / \mathrm{m}^{2}$ reduction in baseline ELI predicts a 2.5 -fold increase of risk of aortic valve events, 1.93-fold increase in total mortality, and 2.28 increase in combined mortality and hospitalization for heart failure.

Hemodynamic characteristics of the normal aortic valve showed that there is a significant connection between PG (TPGmax) in the left ventricle outflow tract (LVOT) which is actually dynamic pressure responsible for blood flow through the valve, and the size of the EOA of the valve and so-called static pressure (TPGnet-the net pressure drop) which is the PG between LVOT and the ascending aorta. The difference between TPGmax and TPGnet is called pressure recovery and it is due to the conversion of a certain amount of kinetic energy 
(dynamic pressure) to potential energy (static pressure) downstream from the valve (Figure 1). This is called the recovery phenomenon of the myocardium.

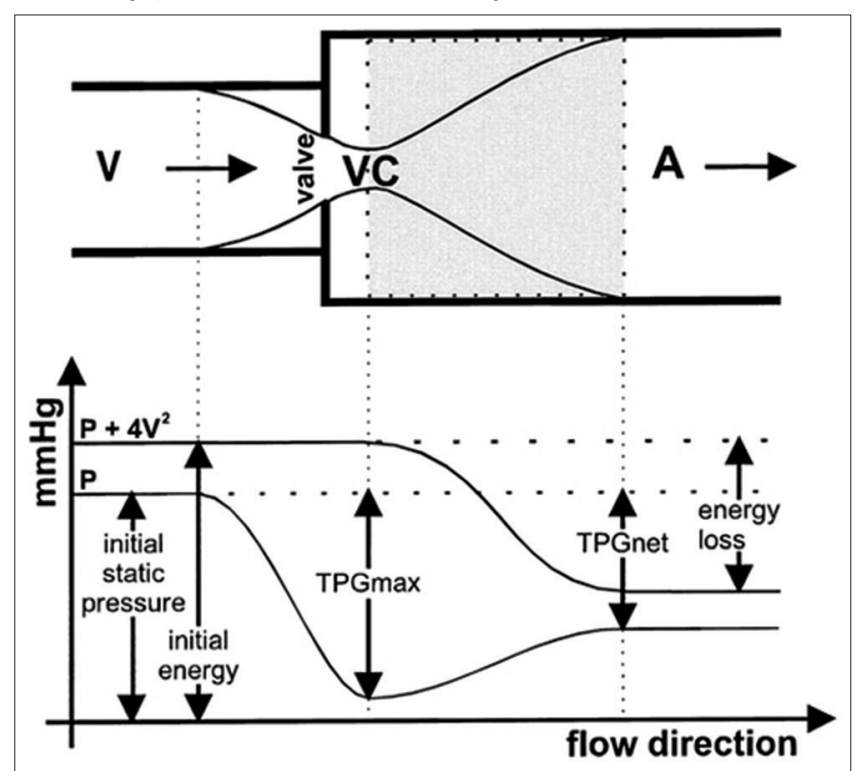

Figure 1: Schematic representation of a system composed of the left ventricle, the aortic valve, and the ascending aorta, with corresponding static pressure $(P)$ and energy in terms of total pressure $(P+4 V 2)$. $V$ indicates left ventricular outflow tact; VC: Vena contracta; and A: Aorta

The energy generated by the ventricle during one cardiac cycle is equivalent to the integral of the pressure-volume diagram (Figure 2, shaded area). The energy per unit volume generated by the ventricle is equivalent to the integral of the pressure diagram divided by the stroke volume. This is roughly equivalent to the average increase in left ventricular pressure from diastole to systole. The ventricle thus creates energy in the form of static pressure, and this energy is converted to gravitational and kinetic energy elsewhere in the circulation [4], [5]. Pressure, gravitational, and kinetic energies in the circulation can be freely converted from one form to another without energy loss.

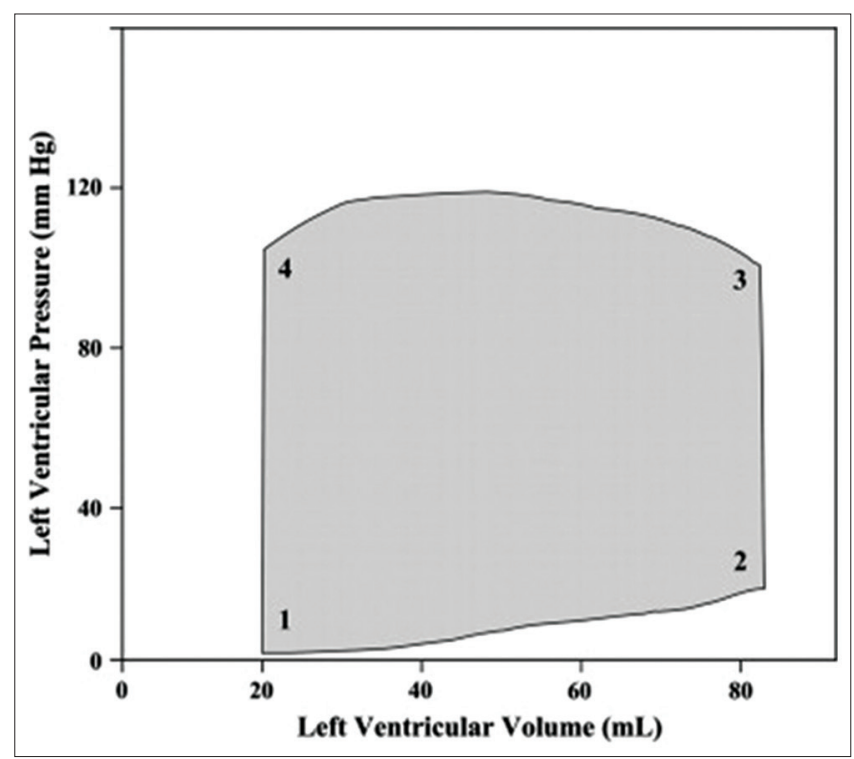

Figure 2: Pressure-volume diagram of one cardiac cycle
In stenotic aortic valve, TPGnet is higher because of compromised flow through the stenotic orifice. The difference between TPGmax and TPGnet is lower which means that there is a bigger energy loss through the aortic valve and that results with worsening of the left ventricle condition expressed with thickness of the wall, first diastolic and later systolic heart failure when fibrosis appear due to subendocardial ischemia [15].

The extent of pressure recovery is determined by the ratio between the valve EOA and the crosssectional area of the ascending aorta, a situation that becomes particularly relevant in patients with moderate to severe AS and small aortas, in whom measurement of AVA by Doppler echocardiography may lead to overestimation of the severity [3], [5], [6], [7]. Conversely, patients with dilation of the ascending aorta have less or no pressure recovery and therefore a more important energy loss for a given valve EOA [15].

Fortunately, pressure recovery can be accounted for calculating the ELI as follows: ELI=[(AVA $\times A A) /(A A-A V A)] / B S A$, where $A A$ is the cross-sectional area of the aorta measured at the sinotubular junction and BSA is the body surface area [3], [14]. Hence, the ELI consists of an adjustment of the Doppler AVA for the size of the ascending aorta (Figure 1) and is thus more or less equivalent to the "recovered" AVA obtained by catheterization [3], [6], [8]. From a physiological standpoint, ELI is superior to Doppler AVA or gradient in the sense that it represents the actual energy loss caused by the stenosis better, and thus the increased burden imposed on the ventricle [10].

Fortunately, when mechanical stresses are relieved and energy loss returns to more normal patterns with valvular reconstruction or replacement, in many situations, such as with AS, the detrimental ventricular remodeling can be reversed. However, in some clinical situations such as long-standing AS, correction of the mechanical stresses, and normalization of the energy loss may not be reflected in reverse remodeling, and the detrimental changes to the myocardium can persist even after the valvular lesion is corrected [13], [16]. Those patients are correlated with worse clinical outcomes, even after surgical reconstruction, due to too late surgery, in stadium when the myocardium of the left chamber has lost its remodeling ability [3], [4], [5].

Thus, the actual relationship of energy loss to changes imposed on the myocardium is more easily understood in the causative relationship concerning pathologic remodeling than it is in reverse remodeling when the energy loss patterns have been normalized.

The main purpose of this study is to present the benefit of using the transvalvular ELI like a parameter that provides a more accurate estimation of the energy loss across aortic valves, the severity of AS, and influence on ventricular function. The second objective is to evaluate the performance of this new index when predicting the mortality rate of patients with AS. 


\section{Methods}

This manuscript defines the importance of energy loss index (ELI) for better understanding the impact of severity of aortic valve stenosis on ventricular function and clinical outcome. The current guidelines [1], [2] make no distinction between catheterization and Doppler echocardiographic measurements of aortic valve parameters; therefore, we put an emphasis on the ultrasound measurements in this manuscript.

A retrospective study was performed on 377 consecutive patients ( 211 men and 166 women; average age $66.4 \pm 9.8$ years) who underwent an echocardiographic evaluation at Zan Mitrev Clinic between February 2002 and June 2020 and was considered to have severe (EOA $\left.\leq 1.0 \mathrm{~cm}^{2}\right)$ AS on the basis of the criteria recommended by the American Heart Association and the European Cardiology Guidelines. Endpoints were defined as death or aortic valve reconstructive surgery (AVRS) within the $1^{\text {st }}$ month after the surgery, like a parameter for early mortality rate, survival within the next 18 years. The measurements were performed using a Philips IE 33 ultrasound system and included the transvalvular flow velocity using continuous-wave Doppler, left ventricular outflow tract velocity using pulsed-wave Doppler, and left ventricular outflow tract diameter. Two-dimensionally directed left ventricular M-mode dimensions and the aortic diameter at the tip of the valve leaflets were measured in the left parasternal long-axis view using the recommendations of the American Society of Echocardiography. With these measurements, we calculated left ventricular stroke volume and $E F$, peak and mean PG, valve EOA and using the modified Bernoulli equation, we calculated the energy loss coefficient $(E O A \times A A) /(A A-E O A)$. It should also be taken into consideration the cardiac output requirements of the patient under normal resting conditions, the EOA, and the energy loss coefficient that were also indexed for the body surface area.

\section{Description of the surgical technique}

After median sternotomy and standard pericardial scission, the aortic arch and right atrium have to be cannulated according to the protocol for aortic valve surgery and the patient is connected to the extracorporeal circulation in a condition of mild hypothermia. Using a mild blood $(\mathrm{k} / \mathrm{mg})$ cardioplegia, suprannular aortotomy is performed and native destructed valve can be extirpated. According to the measurements of AVA, LVOT, aortic annulus, and leaflet dimensions, newly created leaflets can be tailored in a semilunar shape from a standard pericardial patch. After that, every leaflet is sutured on the aortic annually separately, and at the end, intercommisural junctions are created. Subsequently, the closure of the aorta follows and the patient avoids from the extracorporeal machine in a standard way.

\section{Statistical analysis}

A backward stepwise Kruskal-Wallis ANOVA was performed to identify the independent predictors of adverse clinical outcomes, and for dependent predictors, we used Student's t-test for regular distribution, and for predictors, with an irregular distribution, we used Mann-Whitney $U$ Test. The relevant variables tested for this analysis were patients' age and sex, and the following Doppler echocardiographic parameters: Peak TPG, mean TPG, AVA, EOA, indexed valve EOA, ELI, and EF. $p<0.05$ was considered statistically significant.

\section{Results}

Among the 377 patients, with average age $66.3 \pm 9.9$ years, included in this retrospective study. $211(55.97 \%)$ were males and 166 (44.03\%) females. One hundred fourteen $(30.3 \%)$ had severe AS and $263(69.7 \%)$ had combined AS and insufficiency. One hundred $(26.5 \%)$ had a small aortic root with annulus dimensions $<21 \mathrm{~mm}$. Pre-operative characteristics of the patients are showed in Table 1.

Table 1: Pre-operative characteristics of patients

\begin{tabular}{lll}
\hline Etiology & $\mathrm{A}$ & Percent \\
\hline Degenerative & 334 & 88.59 \\
Congenital & 8 & 2.12 \\
Endocarditis & 20 & 5.30 \\
Rheumatic fever & 15 & 3.98 \\
Total & 377 & 100.0 \\
EuroSCORE & $\mathrm{A}$ & Percent \\
$<5$ & 342 & 90.72 \\
$5-15$ & 26 & 6.89 \\
$>15$ & 9 & 2.39 \\
Total & 377 & 100.0 \\
Previous MI & 302 & 80.11 \\
Diabetes & 97 & 25,73 \\
Hyperlipidemia & 273 & 72,4 \\
Hypertension & 350 & 92,8 \\
Smoking & 48 & 12,7 \\
Obesity & 17 & 4,5 \\
COPD & 24 & 6,4 \\
Renal insufficiency & 29 & 7,4 \\
\hline COPD: Chronic obstructive pulmonary disease. & &
\end{tabular}

AVRS was performed on all patients. According to the performed surgery, we divided the patients in four groups. One hundred eighty $(47.7 \%)$ patients got only AVR, $121(32.1 \%)$ patients combination of AVRS and coronary artery bypass surgery (CABG), 33 (8.8\%) AVRS, mitral, and tricuspid valve surgery, and 43 (11.4\%) patients AVRS, mitral, tricuspid valve, aortic surgery, and CABG (Table 2). Mann-Whitney $U$ test (Table 3 ) showed that according to the comorbidities, there were no significant differences between the groups, except for obesity and EuroSCORE.

The results of the univariate analysis of potential predictors of outcome (i.e., death or AVR) are shown in Table 3. 
Table 2: Type of surgery and NYHA classification

\begin{tabular}{|c|c|c|c|c|}
\hline \multirow[t]{2}{*}{ Group } & \multicolumn{3}{|l|}{ The NYHA } & \multirow[t]{2}{*}{ Total } \\
\hline & Staging II & Staging III & Staging IV & \\
\hline \multirow{2}{*}{$\begin{array}{l}\text { Reconstructive surgery with replacement } \\
\text { of three leaflets (N1) }\end{array}$} & 24 & 145 & 11 & \multirow[t]{2}{*}{180} \\
\hline & $13.33 \%$ & $80.56 \%$ & $6.11 \%$ & \\
\hline \multirow{2}{*}{$\begin{array}{l}\text { Combined surgery - reconstructive } \\
\text { surgery with replacement of three leaflets } \\
\text { and CABG (N2) }\end{array}$} & 7 & \multirow{2}{*}{$\begin{array}{l}104 \\
85.95 \%\end{array}$} & \multirow{2}{*}{$\begin{array}{l}10 \\
8.26 \%\end{array}$} & \multirow[t]{2}{*}{121} \\
\hline & $5.79 \%$ & & & \\
\hline Combined surgery - reconstructive & 1 & 25 & & \multirow[t]{2}{*}{33} \\
\hline $\begin{array}{l}\text { surgery with replacement of three leaflets } \\
\text { and mitral or tricuspid valv.surg (N3) }\end{array}$ & $3.03 \%$ & $75.76 \%$ & $21.21 \%$ & \\
\hline Combined surgery - reconstructive & 3 & 30 & & 43 \\
\hline surgery with replacement of three & $6.98 \%$ & $69.77 \%$ & $23.26 \%$ & \\
\hline \multirow{2}{*}{$\begin{array}{l}\text { leaflets and CABG mitr. And tric surg and } \\
\text { aortoplasty (N4) } \\
\text { All groups }\end{array}$} & & & & \\
\hline & 35 & 304 & 38 & 377 \\
\hline
\end{tabular}

A significant $(p<0.001)$ association existed between the outcome and patient age, peak TPG, mean TPG, valve EOA, indexed EOA, energy loss coefficient, and ELI. However, the analysis (Table 4) of the ELI $(p<0.001)$ and the correlation with mortality was a significant independent predictor of the outcome.

Table 3: Differences between performed type of surgery according to comorbidities, etiology, and EuroSCORE (MannWhitney U test)

\begin{tabular}{lllll}
\hline Parameter & $\mathrm{Z}$ & $\mathrm{p}$-level & Valid N & Valid N \\
\hline Diagnosis & 0.77842 & 0.436324 & 211 & 166 \\
$\begin{array}{l}\text { Etiology degenerative-0 congenital-1 } \\
\text { endocarditis-2 rheumatic fever-3 }\end{array}$ & -0.38306 & 0.701672 & 211 & 166 \\
$\begin{array}{l}\text { The New York Heart Association (NYHA) } \\
\text { staging II-0,III-1,IV-2 }\end{array}$ & 0.07883 & 0.937167 & 211 & 166 \\
$\begin{array}{l}\text { EuroSCORE 0-15 } \\
\text { Mitral insufficiency (MI) at anamnesis }\end{array}$ & 1.88283 & 0.059724 & 211 & 166 \\
da-1, ne-0 & -0.26574 & 0.790442 & 211 & 166 \\
Comorbidities (0-No, 1-Yes) diabetes & -1.01659 & 0.309352 & 211 & 166 \\
Comorbidities (0-No, 1-Yes) hyperlipidemia & 0.04796 & 0.961747 & 211 & 166 \\
Comorbidities (0-No, 1-Yes) hypertension & 0.44658 & 0.655180 & 211 & 166 \\
Comorbidities (0-No, 1-Yes) smoking & 2.83951 & 0.004519 & 211 & 166 \\
Comorbidities (0-No, 1-Yes) obesity & -3.75206 & 0.000175 & 211 & 166 \\
Comorbidities (0-No, 1-Yes) COPD & 1.08963 & 0.275875 & 211 & 166 \\
Comorbidities (0-No, 1-Yes) renal & 1.07674 & 0.281598 & 211 & 166 \\
insufficiency & & & & \\
\hline NYHA: New York Heart Association, COPD: Chronic obstructive pulmonary disease. & & \\
\end{tabular}

Thirty-three $(8.7 \%)$ patients who had an ELI $\leq 0.42 \mathrm{~cm}^{2} / \mathrm{m}^{2}$ died early, and $14(3.7 \%)$ died in the second group with ELI index $\geq 0.42 \mathrm{~cm}^{2} / \mathrm{m}^{2}$ (Table 4). Normal subjects had an ELI $>1.35 \mathrm{~cm}^{2} / \mathrm{m}^{2}$, and no overlap existed between these subjects and the patients with AS.

Table 4: Distribution of death patients in correlation with ELI

\begin{tabular}{llll}
\hline Transvalvular aortic gradient (ELI) & \multicolumn{2}{l}{ Mortality } & Total \\
\cline { 2 - 3 } & Exitus letalis & Alive & \\
\hline ELI $\leq 0.42$ & 33 & 175 & 208 \\
& $8.7 \%$ & $92.3 \%$ & $100 \%$ \\
ELI $>0.42$ & 14 & 155 & 169 \\
& $3,7 \%$ & $96.3 \%$ & $100 \%$ \\
All groups & 47 & 330 & 377 \\
\hline
\end{tabular}

Correlation between EAO (EOA of the reconstructed valve) and ELI does not show any influence of EAO separately on ELI, and that is why EAO is not a significant predictor of the clinical outcome when it comes to operated patients (Figure 3). On the other hand, pre-operative values of AVA (Aortic valve area before surgery) have a strong influence on ELI (Figure 4), which means that patients who had more severe express stenotic changes of the aortic valve (smaller AVA) had smaller ELI and that means that they had bigger energy loss through the aortic valve.

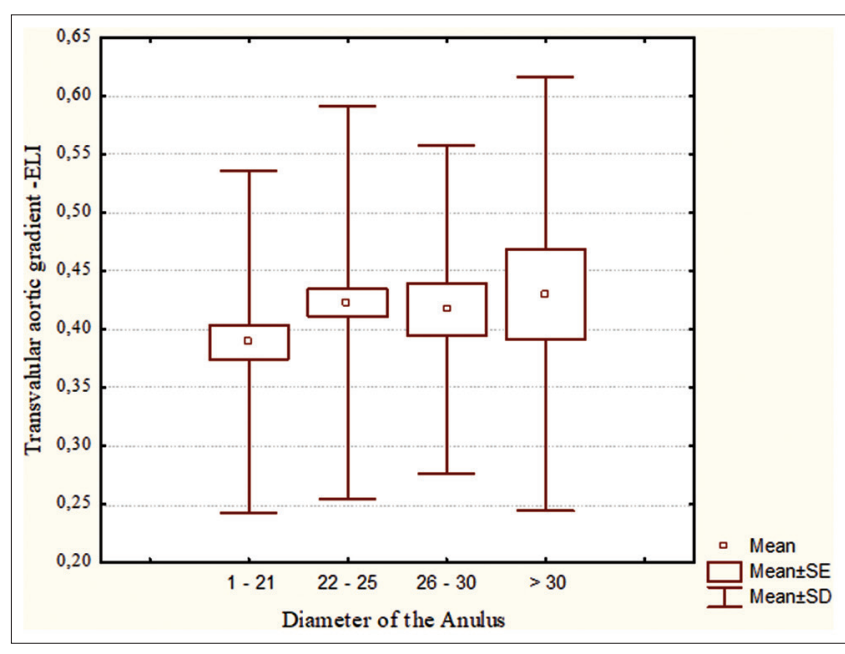

Figure 3: Correlation between EAO and energy loss index

There is no statistical difference between the groups of ELI mean values (Tab.5) Kruskal-Wallis ANOVA: $\mathrm{H}=1683 \mathrm{p}=0.6406$. ELI mean values were the highest in a group with surgery for aortic, mitral, and tricuspid valve, but these data showed no statistically significant difference.

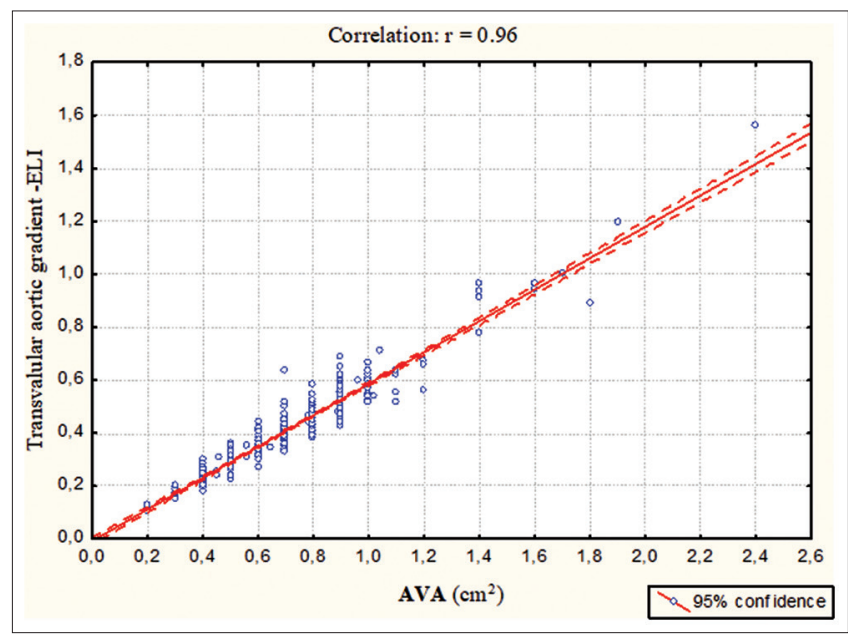

Figure 4: Influence of AVA on energy loss index before the surgery

That was the reason why we analyzed KaplanMeier curve of survival (Figure 5) in correlation with the values of ELI. Using ELI like a parameter, the patients were divided in two groups: one group with $\mathrm{ELI}<0.42$ in which survival after 10 years was $60 \%$, and the other with ELI $>0.42$, in which survival after 10 years was $72 \%$.

\section{Discussion}

Patients who have AS with similar aortic valve EOAs and similar PGs through the LVOT may have different clinical outcomes. The results from our study suggest that not only valve area and PG through the LVOT have an impact on the left ventricular workload. 


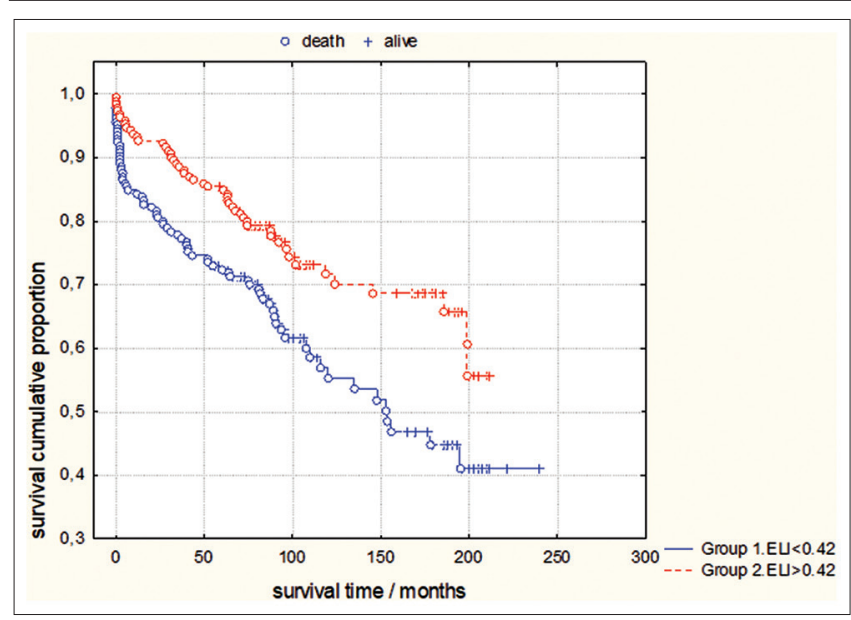

Figure 5: Kaplan-Meier curve of survival in correlation with energy loss index

The noninvasive estimation of energy loss might be useful for the hemodynamic assessment of patients with AS because it reflects more closely the amount of left ventricular energy that is lost during systole due to the obstruction created by the valve, and on the other side takes in consideration myocardium contractility reserve. Several investigators suggested studying the hemodynamic performance of stenotic valves by assessing energy loss [9], [11], [17], [18], [19], [20]. As was described by Hencen recovery phenomenon of myocardium directly depends from the differences between static and dynamic energy during the left ventricle workload. Transvalvular energy loss depends not only from the flow rate and EOA but also from dimensions of the aortic cross-sectional area. Hencen was the first who used Bernoulli equation and calculated the energy loss coefficient (EOA $\times A A) /(A A-$ $E O A)$. These relationships show that in the context of severe AS $\left(E O A<1.0 \mathrm{~cm}^{2}\right)$, a small decrease in EOA results in a dramatic increase in energy loss. The elasticity of the aortic ring and possibility of proportional changing of the EOA with a left ventricle workload in patients with AS is lost because of the pathomorphology of stenosis [21]. This results with lost systolic and diastolic left ventricle function in time [24]. Higher transvalvular energy loss means that the left ventricle has a preserved myocardium with a possibility for recovery after performed surgery. ELI $<0.42$ means that the phenomenon of left ventricle recovery shows that even and after the surgery and correction of stenotic changes of the aortic valve, the left ventricle can still have signs of heart failure. These results agree with those determined in the study of Baumgartner et al. [8], which showed that the pressure recovery phenomenon is clinically relevant mostly in patients with an aortic diameter $<30 \mathrm{~mm}$.

Since 2012, the European Society of Cardiology-European Association for Cardio-Thoracic Surgery guidelines [2] recommended that AVR should be considered in symptomatic patients with paradoxical low-flow, low-gradient AS with normal EF only if comprehensive evaluation suggests significant obstruction. This comprehensive evaluation should include recognition of the pathognomonic features of paradoxical low flow [12], [30], assessment of valve morphology, and, in particular, quantification of valve calcification by echocardiography or preferably by computed tomography, as well as corroboration of hemodynamic severity of the stenosis by stress echocardiography. In light of the results of the present study, calculation of the ELI should also be part of this evaluation given that a large proportion of patients with the paradoxical low flow-low gradient have a small aorta [22], [23], [25], [26], [27], [30].

Thirteen years after the introduction of the ELI, SEAS trial demonstrates that this new stenotic index provides independent and incremental prognostic information in asymptomatic AS patients without known atherosclerotic disease or diabetes. Calculation of the ELI appears most useful in patients with a small aorta and in those with inconsistent grading of stenosis severity on the basis of AVA and gradient [31], [32], [33].

We estimated 377 patients with severe AS. According to the performed surgery, we have four groups of patients (Tables 1-3). The analysis of patients demographic data showed that there is no statistically significant difference between the patient's characteristics. We calculated the average values of ELI and compared the differences between the groups, as shown in Table 5 Kruskal-Wallis ANOVA: $H=1683 p=0.6406$. The average values of ELI were the highest in a group of patients who underwent surgery of aortic, mitral, and tricuspid valve, but that difference did not have any statistical significance. That is the reason why, during further analysis, we analyzed mortality rate in correlation with calculated average values of ELI (Table 4). Furthermore, the correlation between AVA and ELI (correlation $r=0.96$ ) showed a significant proportional influence of AVA on ELI that means that patients with bigger AVA have bigger ELI which in comparison with mortality rate results with a better clinical outcome. Anyways analysis of postoperative EAO does not show statistical significance.

Kaplan-Meier - survival curve pointed that patients with ELI $<0.42$ have $80 \%$ chance of survival

Table 5: Transvalvular ELI-distribution of mean values

\begin{tabular}{|c|c|c|c|c|}
\hline Group & Means & SD & Min & Max \\
\hline $\begin{array}{l}\text { Reconstructive surgery with replacement } \\
\text { of three leaflets (N1) }\end{array}$ & 0.4051 & 0.1418 & 0.1183 & 1.0042 \\
\hline $\begin{array}{l}\text { Combined surgery - reconstructive } \\
\text { surgery with replacement of three leaflets } \\
\text { and CABG (N2) }\end{array}$ & 0.4081 & 0.1596 & 0.1036 & 1.1950 \\
\hline $\begin{array}{l}\text { Combined surgery - reconstructive } \\
\text { surgery with replacement of three leaflets } \\
\text { and mitral or tricuspid valv.surg (N3) }\end{array}$ & 0.4587 & 0.2524 & 0.1952 & 1.5630 \\
\hline $\begin{array}{l}\text { Combined surgery - reconstructive } \\
\text { surgery with replacement of three } \\
\text { leaflets and CABG mitr. And tric surg and } \\
\text { aortoplasty (N4) }\end{array}$ & 0.4318 & 0.1540 & 0.2215 & 0.9308 \\
\hline All groups & 0.4138 & 0.1613 & 0.1036 & 1.5630 \\
\hline
\end{tabular}


on 24 months (2 years), $70 \%$ on 60 months (5 years), $50 \%$ survival on 150 months (12 years), and $40 \%$ on 200 months (more than 16 years). In a group of patients with ELI $>0.42$, the survival rate on 24 months (2 years) is $95 \%, 80 \%$ on 72 months (6 years), $70 \%$ on 150 months, and 55\% after 200 months (18 years). Patients with ELI $<0.42$ have a high early mortality rate up to $8.75 \%$, whereas in those groups where ELI $>0.42$ early mortality rate was $3.71 \%$, the above-mentioned parameters correlate with actual medical literature [3], [17], [28], [29], [35].

The obtained results correlate with the results of other in vivo studies, which showed that the ELI was superior to the valve EOA in predicting adverse clinical outcomes in patients with moderate to severe AS. Therefore, an ELI $<0.50 \mathrm{~cm}^{2} / \mathrm{m}^{2}$ should probably be considered a critical value below which patients should be closely monitored for the appearance of symptoms [1], [34], [37]. Bevan made a retrospective review of the mortality data for patients with biological or mechanical AVR, collected from Society for Thoracic surgery, and according to this data, the adjusted mortality is similar between mechanical and biological prosthesis, and for 15 years it ranges up to $80 \%$ [37].

\section{Limitations of the study}

The main limitation of this study is that this is a retrospective, single-center study. As mentioned in the discussion, the impact of the ELI on the clinical outcome might be affected by possible selection bias. Another limitation of this study is the possible change in the aortic diameter after AVR. Botzenhardt et al. [36] reported that aortic diameters decreased after removal of the diseased valve. Therefore, changes in aortic diameter after AVR might affect these results.

\section{Conclusions}

The results of this study point that transvalvular ELI can be used for estimation of the severity of aortic valve stenosis. This index is more accurate than the currently used parameters to estimate work loss, and it has the advantage of being easily measurable using Doppler echocardiography.

Moreover, the results of our investigation clearly suggest that this index is a better predictor of the possible outcomes than the currently recommended index of severity, like an aortic valve area.

Prospective studies are necessary to further document the validity of this new index in the clinical situation.

\section{Acknowledgments}

We would like to thank ZMC staff for dedication and passion in the treatment of patients.

\section{References}

1. Bonow RO, Carabello BA, Kanu C, de Leon AC, Faxon DP, Freed MD, et al. ACC/AHA 2006 guidelines for the management of patients with valvular heart disease: A report of the American college of cardiology/American heart association task force on practice guidelines (writing committee to revise the 1998 guidelines for the management of patients with valvular heart disease): Developed in collaboration with the society of cardiovascular anesthesiologists: Endorsed by the society for cardiovascular angiography and interventions and the society of thoracic surgeons. Circulation. 2006;114(5):e84-231. https://doi. org/10.1016/j.jacc.2008.05.007

PMid: 16880336

2. Vahanian A, Alfieri $O$, Andreotti $F$, Antunes MJ, BaronEsquivias G, Baumgartner $\mathrm{H}$, et al, The Joint Task Force on the Management of Valvular Heart Disease of the European Society of Cardiology (ESC) and the European Association for Cardiothoracic Surgery (EACTS). Guidelines on the management of valvular heart disease (version 2012). Eur Heart J. 2012;33(19):2451-96. https://doi.org/10.1093/eurheartj/ehs109 PMid:22922415

3. Garcia D, Pibarot P, Dumesnil JG, Sakr F, Durand LG. Assessment of aortic valve stenosis severity: A new index based on the energy loss concept. Circulation. 2000;101(7):765-71. https://doi.org/10.1161/01.cir.101.7.765

PMid:10683350

4. Bahlmann E, Gerdts E, Cramariuc D, Gohlke-Baerwolf C, Nienaber CA, Wachtell $\mathrm{K}$, et al. Prognostic value of energy loss index in asymptomatic aortic stenosis. Circulation. 2013;127(10):1149-56. https://doi.org/10.1161/ circulationaha.112.078857

PMid:23357717

5. Heinrich RS, Marcus RH, Ensley AE, Gibson DE, Yoganathan AP. Valve orifice area alone is an insufficient index of aortic stenosis severity: Effects of the proximal and distal geometry on transaortic energy loss. J Heart Valve Dis. 1999;8(5):509-15. PMid:10517392

6. Colan SD. Ventricular function in volume overload lesions In: Fogel MA, editor. Ventricular Function and Blood Flow in Congenital Heart Disease. Philadelphia, PA: Blackwell; 2005. p. 205-22.

7. Colan SD. Ventricular function in pressure overload lesions. In: Fogel MA, editor. Ventricular Function and Blood Flow in Congenital Heart Disease. Philadelphia, PA: Blackwell; 2005. p. 187-204.

8. Baumgartner H, Stefenelli T, Niederberger J, Schima H, Maurer G. Overestimation of catheter gradients by Doppler ultrasound in patients with aortic stenosis: A predictable manifestation of pressure recovery. J Am Coll Cardiol. 1999;33(6):1655-61. https://doi.org/10.1016/s0735-1097(99)00066-2 PMid: 10334438

9. Garcia D, Dumesnil JG, Durand L, Kadem L, Pibarot P. Discrepancies between catheter and Doppler estimates of valve effective orifice area can be predicted from the pressure recovery phenomenon. J Am Coll Cardiol. 2003;41:435-42. 
https://doi.org/10.1016/s0735-1097(02)02764-x

PMid:12575972

10. Yoganathan AP, Recusani F, Valdez-Cruz L, Sung HW, Sahn DJ. Oblique flow vectors from dispersing jets produce the velocity overestimation on angle corrected continuous wave Doppler studies: In vitro laser Doppler investigations. Circulation. 1987;76(4):355.

11. Voelker W, Reul H, Stelzer T, Schmidt A, Karsch K. Pressure recovery in aortic stenosis: An in vitro study in a pulsatile flow model. J Am Coll Cardiol. 1992;20(7):1585-93. https://doi. org/10.1016/0735-1097(92)90454-u

PMid:1452933

12. Garcia D, Pibarot P, Dumesnil JG, Sakr F, Durand LG. Assessment of aortic valve stenosis severity: A new index based on the energy loss concept. Circulation. 2000;101(7):765-71. https://doi.org/10.1161/01.cir.101.7.765 PMid: 10683350

13. Zoghbi WA, Farmer KL, Soto JG, Nelson JG, Quinones MA. Accurate non-invasive quantification of stenotic aortic valve area by Doppler echocardiography. Circulation. 1986;73(3):452-9. https://doi.org/10.1161/01.cir.73.3.452 PMid:3948355

14. Scotten L, Walker D, Dutton J. Modified gorlin equation for the diagnosis of mixed aortic valve pathology. J Heart Valve Dis. 2002;11(3):360-8.

PMid:12056728

15. Garcia D, Pibarot P, Durand L. Analytical modelling of the instantaneous pressure gradient across the aortic valve. J Biomech. 2005;38(6):1303-11. https://doi.org/10.1016/j. jbiomech.2004.06.018

PMid: 15863115

16. Gjertsson P, CaidahIK, Svensson G, Wallentin I, Bech-Hanssen O. Important pressure recovery in patients with aortic stenosis and high Doppler gradients. Am J Cardiol. 2001;88(2):139-44. https://doi.org/10.1016/s0002-9149(01)01608-3

PMid: 11448410

17. Gross-Sawicka E, Pringle T, Lipworth B. Aortoseptal angulation and left ventricular hypertrophy pattern: An echocardiographic study in patients with aortic valve stenosis. $J$ Am Soc Echocardiogr. 1991;4(6):583-8. https://doi.org/10.1016/ s0894-7317(14)80217-4

PMid:1836950

18. White R, Obuchowski N, Gunawardena S, Lipchik E, Lever H, Van Dyke C, et al. Aortic inflow tract obstruction in hypertrophic cardiomyopathy: Presurgical and postsurgical evaluation by computed tomography magnetic resonance imaging. Am J Card Imaging. 1996;10(1):1-13.

PMid:8680128

19. Come P, Pringle T, Lipworth B. Doppler evidence that true left ventricular to aortic pressure gradients exist in hypertrophic cardiomyopathy. Am Heart J. 1988;116(5):1253-61. https://doi. org/10.1016/0002-8703(88)90448-6

PMid:3189142

20. Bermejo J, Edreman R, Feijoo J, Moreno MM, GomezMoreno P, Garcia-Fernendez MA. Clinical efficacy of Doppler-echocardiographic indices of aortic valve stenosis: A comparative test-based analysis of outcome. J Am Coll Cardiol. 2003;41(1):142-51. https://doi.org/10.1016/ s0735-1097(02)02627-x

PMid:12570957

21. Tobin JR, Rahimtoola SH, Blundell PE, Swan HJ. Percentage of left ventricular stroke work loss. A simple hemodynamic concept for estimation of severity in valvular aortic stenosis. Circulation. 1967;35(5):868-79. https://doi.org/10.1161/01.cir.35.5.868 PMid:6021776
22. Oh JK, Taliercio CP, Holmes DR, Reeder GS, Bailey KR, Steward JB, et al. Prediction of the severity of aortic stenosis by Doppler aortic valve area determination: Prospective Doppler-catheterization correlation in 100 patients. J Am Coll Cardiol. 1988;11(6):1227-34. https://doi. org/10.1016/0735-1097(88)90286-0

PMid:3366997

23. Dumesnil JG, Yoganathan AP. Valve prosthesis hemodynamics and the problem of high transprosthetic pressure gradients. Eur J Cardiothorac Surg. 1992;6(1):S34-8. https://doi. org/10.1016/1010-7940(92)90019-t

\section{PMid:1389276}

24. Tongue AG, Dumesnil JG, Laforest I, Theriault C, Durand LG, Pibarot P. Left ventricular longitudinal shortening in patients with aortic stenosis: Relationship with symptomatic status. J Heart Valve Dis. 2003;12(2):142-9. https://doi.org/10.1016/ s0735-1097(02)81885-

PMid: 12701783

25. Mascherbauer J, Schima H, Maurer G, Baumgartner H. Doppler assessment of mechanical aortic valve prostheses: Effect of valve design and size of the aorta. J Heart Valve Dis. 2004;13(5):823-30.

PMid: 15473486

26. Travis BR, Leo HL, Shah PA, Frakes DH, Yoganathan AP. An analysis of turbulent shear stresses in leakage flow through a bileaflet mechanical prostheses. J Biomech Eng. 2002;124(2):155-65. https://doi.org/10.1115/1.1448519 PMid: 12002124

27. Stewart SF, Herman BA, Nell DM, Retta SM. Effects of valve characteristics on the accuracy of the Bernoulli equation: A survey of data submitted to the U.S. FDA. J Heart Valve Dis. 2004;13(3):461-6.

PMid:15222294

28. Knebel F, Gliech V, Walde T, Eddicks S, Konertz W, Baumann G, et al. High concordance of invasive and echocardiographic mean pressure gradients in patients with a mechanical aortic valve prosthesis. J Heart Valve Dis. 2005;14(3):332-7. PMid: 15974527

29. Strüber M, Campbell A, Richard G, Laas J. Hydrodynamic function of tilting disc prostheses and bileaflet valves in double valve replacement. Eur J Cardiothorac Surg. 1996;10(6):422-7. https://doi.org/10.1016/s1010-7940(96)80109-6

\section{PMid:8817137}

30. Yoganathan AP, Travis BR. Fluid dynamics of prosthetic valves In: Otto C, editor. The Practice of Clinical Echocardiography. $2^{\text {nd }}$ ed. Philadelphia, PA: WB Saunders; 2002. p. 50-52434.

31. Hartrumph M, Albes JM, Krempl T, Rudolph V, Wahlers T. The hemodynamic performance of standard bileaflet valves is impaired by a tilted implantation position. Eur $\mathrm{J}$ Cardiothorac Surg. 2003;23(3):283-91. https://doi.org/10.1016/ s1010-7940(02)00804-7 PMid: 12614795

32. Travis BR, Heinrich RS, Ensley AE, Gibson DE, Hashim S, Yoganathan AP. The hemodynamic effects of mechanical prosthetic valve type and orientation on fluid mechanical energy loss and pressure drop in in vitro models of ventricular hypertrophy. J Heart Valve Dis. 1998;7(3):345-54.

PMid:9651851

33. Fisher J. Comparative study of the hydrodynamic function of six size $19 \mathrm{~mm}$ bileaflet heart valves. Eur J Cardiothorac Surg. 1995;9(12):692-6. https://doi.org/10.1016/ s1010-7940(05)80127-7

PMid:8703490

34. Pibarot P, Garcia D, Dumesnil JG. Energy loss index in aortic stenosis: From fluid mechanics concept to clinical application. 
Circulation. 2013;127(10):1101-4

PMid:23479666

35. Thourani VH, Keeling WB, Sarin EL, Guyton RA, Kilgo PD, Dara $A B$, et al. Impact of preoperative renal dysfunction on long-term survival for patients undergoing aortic valve replacement. Ann Thorac Surg. 2011;91(6):1798-806. https:// doi.org/10.1016/j.athoracsur.2011.02.015

PMid:21536247
36. Botzenhardt F, Hoffmann E, Kemkes BM, Gansera B. Determinants of ascending aortic dimensions after aortic valve replacement with a stented bioprosthesis. J Heart Valve Dis. 2007;16(1):19-26.

PMid:17315379

37. Bevan GH, Zidar DA, Josephson RA, Al-Kindi SG. Mortality due to aortic stenosis in the United States, 2008-2017. JAMA. 2019;321(22):2236-8. https://doi.org/10.1001/jama.2019.6292 PMid:31184728 